${ }^{I}$ Universidade Federal do Rio de Janeiro (UFRJ)

Programa de Pós-Graduação em Sociologia e Antropologia, Brasil

marcoatg@terra.com.br

Marco Antonio Gonçalves'

\title{
DOMÉSTICA: UMA ETNOGRAFIA INDISCRETA
}

Doméstica. (2012). Direção de Gabriel Mascaro. 75 min.

Doméstica é uma palavra tão familiar na cultura brasileira que quem pro- ser e não ser da família, a inclusão e a exclusão, o afeto e a ordem, o lazer e o trabalho, a ajuda e a obrigação são dilemas e contradições que engendram o complexo significado da profissão de doméstica. Esta conceituação encontra plena significação na fala de uma "patroinha": "Ela mora aqui, ajuda em casa, é da família".

Ao se abordar o tema "empregada doméstica" é comum projetar esta instituição brasileira como fundamentada na sociedade patriarcal e escravocrata do século XVI, ressaltando a continuidade da exploração nas relações de trabalho doméstico até os dias atuais. Gabriel Mascaro resiste, felizmente, em se aproximar do tema, enquadrando-o em uma narrativa sociológica explicativa das relações so- 
ciais e de trabalho no Brasil. O filme aborda as domésticas através de um mosaico de possibilidades, diferentes experiências em que o espectador vai se aproximando desta complexa categoria social. Doméstica é um filme-documentário sobre as relações entre patrões/patroas e domésticas na sociedade brasileira contemporânea. Em vez de buscar um significado, o filme propõe uma desconstrução dos significados do senso comum de modo a revelar, justamente, sua potência de significação na sociedade brasileira.

Assim sendo, o diretor não assume nenhum a priori sobre domésticas, deixando emergir sua conceituação das relações engendradas pelo próprio filme. Doméstica não é atributo de uma classe social específica, nem mesmo de um gênero, como fica claro nas narrativas do filme, mas um conceito que, para além dos sujeitos que o encarnam, revela uma condição essencial para pensar as relações sociais na sociedade brasileira.

O grande mérito de Doméstica é o de escapar de um quadro explicativo que banaliza a compreensão destas relações de trabalho enquadradas como pertencendo a formas pré-capitalistas de exploração. A lente subjetiva ou uma "etnografia indiscreta" aposta na própria mimésis do subjetivo como forma de descrição densa desta relação, escapando do olhar alheio e intruso, optando pela própria revelação da relação através da câmera que simula uma simetria apoiada no terreno da subjetividade: patrões e empregadas são, na verdade fílmica, personagens, e este fato propicia o melhor meio de compreensão desta complexa relação.

Algumas curtas apresentações definem o método adotado que irá nos permitir adentrar no mundo das domésticas. $\mathrm{O}$ dispositivo de filmagem acionado em Doméstica se constitui em passar a câmera para as mãos dos "patrões", os adolescentes que, na condição mesma de personagens, filmam, sobretudo, uma relação. Este tipo de dispositivo adotado por Doméstica não parece querer ser apenas uma técnica de captura de imagens centrada no ponto de vista dos "patrões" como querendo revelar uma "perspectiva"; tampouco segue a tendência do cinema contemporâneo que tem dado importância às "imagens pessoais” produzidas pelos próprios sujeitos fílmicos. A técnica de captura de imagens em Doméstica está a serviço de um método de investigação que é a potência do próprio filme: revelar as domésticas a partir de uma relação com aqueles que elas cuidam e ajudam a criar.

Este ponto parece ser crucial não apenas para o entendimento do filme, mas para a compreensão de doméstica como uma instituição. Quem filma não são os "patrões" que pagam o salário das empregadas, mas os adolescentes que mantêm com elas uma relação radicalmente subjetiva. É desta subjetividade, de sua problematização, que trata o filme. Apresenta uma complexa rede de delicadas relações apreendidas através de seu ponto nevrálgico que é a subjetividade, qua- 
lidade por excelência desta relação que nos convida a fazer uma reflexão sobre o modo pelo qual os brasileiros constroem a sociabilidade: entre o próximo e o distante; entre o cordial e o violento; entre a igualdade e a hierarquia; entre a ajuda e a exploração; entre a obediência e o mando.

Deste modo, a câmera subjetiva em Doméstica, seu minimalismo, captura uma dimensão profunda e complexa de uma relação social. Ao acionar o dispositivo da subjetividade nos faz compreender de um modo apropriado o fenômeno "empregada doméstica” que atravessa séculos e resiste até os dias de hoje como pedra fundamental da sociedade brasileira. Mas como abordar um tema que pode facilmente ser caricaturado a partir da dimensão da exploração e submissão? Não resta alternativa senão a de abordá-lo em seu aspecto mais central: no plano da subjetividade que o engendra, o institui e o caracteriza como uma relação social basilar. Evocamos aqui o paradoxo vivido por Joaquim Nabuco, o grande abolicionista, que quando consegue extirpar a escravidão confessa ter "saudade do escravo", significando uma relação "protetora", "afetiva", eminentemente subjetiva, o que forjou a "relação social à brasileira”. A afeição, o cuidado, a atenção, a ajuda é o que é enfatizado nestas relações entre patrões e empregadas que se constituem a partir do trinômio: afetividade, reciprocidade e desigualdade (ver Velho, 20I 2: 20; Buarque de Holanda, I936; Freyre, I933, I936). Afetividade, neste campo de contradições das relações entre patrões e empregados, congrega tanto a tensão e o conflito quanto as concepções de amizade (Resende, 200I: 256-257).

Vejamos alguns destes personagens e suas relações.

Vavá, Vanusa é motorista e empregada da família de Neto há I7 anos. Neto, procurando conhecer Vanusa adentra em seu universo, em seu quarto e, mais especificamente, em seu armário. Surge uma caixinha em formato de coração e um livro que ela lê para aprender a lidar com o sofrimento causado pelo envolvimento de seu filho com as drogas. Neto formula as perguntas com delicadeza e parece que gosta, através do jogo da câmera, de poder descobrir quem é Vavá, de se aperceber dela de outro modo, de inverter a relação de cuidado, de atenção. O filme subverte as relações quando põe o foco em Vavá. A cegueira narcísica de uma suposta violência exploratória é rompida pela câmera que afirma o interesse pela doméstica, por sua história, por seu mundo. A câmera passa a ser esta pedagogia de aprendizado sobre o outro; agora, é a doméstica que está em cena, é ela que fala e é falada por seus patrões. A câmera propicia este conhecimento. Quem quer conhecer as empregadas são os patrões e, através de suas lentes, o espectador é cúmplice deste processo de aprendizado que o remete, irremediavelmente, às suas próprias experiências com as domésticas. Por outro lado, a câmera e a posição assumida por Neto 
propiciam a Vanusa revelar, externar suas emoções, compreendendo-se ao compreender a natureza mesma da relação subjetiva que engendra com os patrões: ouve um poema do rádio e repete os versos em uníssono com o locutor; fala com o filho ao telefone sobre o porquê deixou-o preso sem as chaves de casa para sair; por um instante, antes de começar a guardar as toalhas de banho no armário, pensa em seu filho e se emociona; dirigindo o carro diz que "acha chique dirigir"; fala sobre sua separação referindo-se a seu marido como o "pai dos meus filhos"; durante os 24 anos de casamento diz que o marido sempre a traía; canta uma música de amor quando está sozinha no carro e, sabendo que a câmera continua ligada, libera sua emoção ao cantar a dificuldade de ter um amor correspondido.

Esta inversão de perspectiva, ao coincidir com o "girar a câmera" na direção das domésticas, ganha plena potência quando uma das adolescentes aparece diante da câmera usando a lente como espelho, ajeitando seu cabelo antes de começar a gravar a entrevista com sua doméstica. O "girar a câmera" na direção da doméstica encerra um gesto ritual que aciona novas significações. A "patroinha" formula a primeira pergunta: "como chegou a São Paulo?" E ela responde: seu pai vendeu dois bois e deu o dinheiro para seu marido como "dote" de casamento. O marido a decepciona, aluga um quarto "debaixo do chão", não a deixa sair de casa e o resto do dinheiro gasta em bebida.
Neste ponto a "patroinha" comenta: "Que horror!", tomando consciência da história no momento mesmo em que é narrada. A "patroinha" continua: "bem, o primeiro casamento foi ruim, mas o segundo está ótimo, não?" E a empregada diz: "não, não está bem não...", e se cala.

A empregada está na cozinha fazendo um pão de trança. Coloca-o no forno. A família senta à mesa e a empregada ocupa um lugar de destaque durante a cerimônia judaica que se desenrola. O pai fala em hebraico, uma moça explica para a empregada o ritual do pão, revelando que ele está coberto para não ficar com ciúme do vinho. A empregada come do próprio pão que preparou para o ritual. Mais tarde ficamos sabendo que o fato de ela estar sentada à mesa é derivado de um sonho que teve e foi contado para "patroinha": no sonho, participava da cerimônia do shabbat. Propiciado pelo filme, seu sonho vira realidade e ela está sentada à mesa, comendo o pão e tomando o vinho. Na mesma chave do conhecimento e da inversão de papéis, a "patroinha" pergunta à empregada como ela imaginava que eram os judeus antes de ir trabalhar naquela casa. Impulsionada por ocupar o centro da filmagem, responde com franqueza: "achava que era gente ruim... já tinha trabalhado para uns judeus e tinha sido muito judiada". Na continuidade, diz que quando começou a trabalhar na casa estranhou a comida, era fraca, não sustentava, e depois foi se habituando, gostando e, agora, faz a comida 
e diz que adora. Interessante ressaltar que este "se habituar" enfatiza um processo de transformação que sofre ao passar a conviver com sua nova "família", na casa em que passa a trabalhar. O "habituar", o "acostumar-se" parecem categorias-chave na experiência da doméstica que, remetida ao universo da casa, da família, da intimidade, pode se transformar através de um processo de "familiarização", sendo, portanto, afetada, mudando de gosto, modificando seu modo de compreender o mundo. Porém, a transformação engendrada pela doméstica é de mão dupla: ao mesmo tempo em que é criada (transformada pela relação), cria (os filhos dos patrões; a comida).

Uma outra doméstica, de toalha na cabeça, escuta reagge e dança. A patroa vem até a sala e pede para ela abaixar o volume. Aparece varrendo debaixo do sofá, tirando o pó, arrumando a casa durante a madrugada. A empregada passou a ter hábitos noturnos, trabalha enquanto a casa dorme. Este bloco revela a cumplicidade entre quem filma e quem é filmada, uma relação de intimidade que garante o sucesso desta personagem que se mostra alegre, extrovertida e, ao mesmo tempo, triste e trágica. Sua fala tem humor e violência, abnegação e crítica. Escuta no celular o hino do seu time de futebol, dorme apoiada na máquina de lavar e, às 23h54, dorme debruçada sobre o sofá enquanto o limpava. Trabalha nesta casa há I3 anos e diz que já passou mais tempo na casa dos patrões do que passou com sua mãe; tem saudade de casa quando fica sozinha no quarto, mas sua casa tem tanto problema que prefere ficar longe. Vai para casa de 15 em I5 dias, dependendo das necessidades da família. Diz que ficou três meses sem tirar folga cuidando da avó da "patroinha", e nunca imaginou que estes seriam os últimos meses de vida de seu próprio filho, tragicamente assassinado. Faz queixa, chora e diz que se sentiu roubada pelo trabalho. Mostra seu quarto, apresenta o colchão ortopédico e o ventilador que ganhou da patroa, dizendo que ali se sente em casa! Frase proferida com ambiguidade e jamais saberemos se está ironizando "o sentir-se em casa” ou se está falando a verdade, provavelmente as duas coisas simultaneamente.

A adolescente diz que Lena, a empregada, é como se fosse uma irmã, para quem conta seus segredos, suas transas amorosas. A empregada aparece arrumando o quarto da adolescente enquanto a mãe desta, a patroa, cuida do bebê, filho da empregada. A adolescente recorda o modo como sua mãe anunciou que a empregada ia ter um filho: "a família vai aumentar". A empregada é falada pela patroa, é quem narra uma relação, contando que Lena, a empregada, nasceu na fazenda de sua família, viu Lena pequena e quando cresceu a patroa a trouxe para Salvador. A - "patroinha" complementa, dizendo que a relação com a empregada é muito boa, "não é uma relação de patroa/empregada, é mais do 
que isso, ela é da família, aqui não tem isso, todo muito senta junto na mesa...". O quarto de Lena é apresentado, com a ironia peculiar que constitui esta relação, como "suíte master". O quarto fica fora da casa e parece apertado através das lentes da câmera: uma enorme tv, cama, berço, estante, quadro contendo fotos de sua filha, Fernandinha, desde que nasceu. Fotos que revelam a relação de proximidade com a família: a patroa trocou a primeira fralda, deu o primeiro banho, e diz "Lena é minha filha", emociona-se ao falar do nascimento de Fernandinha, concluindo que quando se "dá para uma pessoa... se entrega por inteira...”. Porém, neste mesmo instante, retoma o discurso de patroa e diz que Lena "não é eterna aqui, se os nossos filhos não são eternos, quanto mais uma pessoa que ajuda...". Admite que o trabalho doméstico cansa, é repetitivo e que a empregada, um dia, pode não querer mais fazê-lo: "no momento em que ela quiser sair a gente vai sentir muito, mas sendo a vontade dela...". Lena, em seu quarto, passa creme hidratante nas pernas enquanto assiste à tv, pega a sua filha no berço e a põe para dormir em seu colo.

Agora estamos em um ambiente popular, em um bairro periférico da cidade de São Paulo. Uma menina negra chamada Bia é cuidada por Flávia que é a empregada da empregada. Este bloco coloca o paradoxo da "empregada da empregada" que resume, por si só, todas as contradições desta complexa definição do que significa doméstica na sociedade brasileira. Flávia e Bia brincam no sofá escutando rádio. Dá banho no menino, irmão de Bia, que tem problemas de locomoção. Flávia conta para Bia sua estória: o marido a estava traindo com uma garota de programa. Sofreu muito nessa vida, ficou grávida de trigêmeos, apanhou do marido, levou chutes na barriga e perdeu os bebês. Teve hemorragia na hora, ficou com febre e desmaiou de dor, acordando no hospital. Depois deste episódio não quer mais saber de homem. Diz que a patroa é boa, e ela também é empregada: "quando não vê as coisas direitas reclama, mas me ajuda muito". Toma a cena, passa a ser o centro do interesse do filme: segura o celular como um microfone e canta, dando um show para a câmera e para as crianças.

Jeniffer, de 16 anos, faz o curso médio, tem aulas de teatro e diz que é cuidada pelo seu "anjo da guarda", que é o empregado doméstico. $\mathrm{O}$ empregado aparece limpando o cocô do cachorro, as lixeiras do banheiro, lavando a louça. Jeniffer, por trás da câmera, conta que ele chegou à sua casa numa época complicada de sua vida, tinha se separado da mulher, uma historia triste: "Minha mãe presenciou tudo isso e chamou ele para cuidar de mim". "Ele não se abre, vive no mundo dele". Dia de Natal. O empregado está presente na festa, todos se abraçam e festejam, se beijam e comemoram. Sérgio serve seu prato de comida, se afasta e come sozinho na varanda. Este bloco, mais uma vez, revira o signi- 
ficado de doméstica, um homem, um "anjo da guarda" é quem realiza as tarefas da casa.

Numa outra história, um adolescente fala para sua empregada que vai fazer um documentário sobre sua vida e pede que ela assine a autorização. Pergunta: “tudo bem?”. Ela diz que sim, assina o papel e continua secando os pratos. A patroa, quando adentra a cozinha, pergunta sobre o capítulo da novela que deixou de assistir. Sentada à mesa, pede um garfo e uma faca, enfatizando o "por favor". A patroa diz que conhece Lucimar desde que nasceu porque ela é filha da caseira da sua bisavó. Mostram fotos de Lucimar pequena com a patroa, as duas de mãos dadas, depois meninas, brincando juntas na fazenda da bisavó. A patroa conta que, quando ia passar férias em Valença, a primeira coisa que pedia era para brincar com Lucimar e que jamais imaginou que ela fosse um dia trabalhar como empregada em sua casa. Reconhece que no começo foi difícil: tinha que se impor como patroa, pois a considerava uma amiga. Depois o adolescente pergunta a Lucimar quando foi que começou a trabalhar.
Ela diz que foi aos I 4 anos, já sabia arrumar, passar roupa, cozinhar. Lucimar está tímida. O menino pergunta o que ela sabe fazer melhor. Responde que faz bolo muito bem. Ela sorri. Ele pergunta se ela gosta de usar uniforme, ela diz que sim. "Você se sente incomodada de andar de uniforme na rua?" "Não, não sinto não". "A relação com minha mãe ficou estranha depois que você veio trabalhar aqui, depois da amizade?". Lucimar faz uma pausa e diz que a relação vai amadurecendo e complementa que tem a oportunidade de estar no Rio de Janeiro, considera que tem liberdade e declara que "gosta disso".

Olha o álbum de fotos que testemunham sua relação com sua amiga/ patroa e timidamente, sorrindo, passa as páginas devagar. Num momento deste bloco, enquanto as imagens percorrem as fotos da infância das duas amigas, hoje patroa e empregada, surge a música Blowin' in the wind, cantada por Bob Dylan, que resume de uma só vez a pergunta posta pelo filme sobre o significado de doméstica na sociedade brasileira: "The answer, my friend, is blowin' in the wind, the answer is blowin' in the wind". 
606

Marco Antonio Gonçalves é professor do Programa de PósGraduação em Sociologia e Antropologia da Universidade Federal do Rio de Janeiro (PPGSA-UFRJ), Pesquisador do CNPq, Doutor em Antropologia pelo Programa de PósGraduação em Antropologia Social do Museu Nacional/UFRJ. Entre seus principais livros estão: Traduzir o outro: etnografia e semelhança (2010); O real imaginado. Etnografia, cinema e surrealismo em Jean Rouch (2008); O mundo inacabado: ação e criação em uma cosmologia amazônica (200I). 


\section{REFERÊNCIAS BIBLIOGRÁFICAS}

Buarque de Holanda, Sérgio. (1936). Raízes do Brasil. Rio de Janeiro: José Olympio.

Freyre, Gilberto. (1936). Sobrados e mucambos. Decadência do patriarcado rural e desenvolvimento urbano. Rio de Janeiro: José Olympio.

Freyre, Gilberto. (I933). Casa grande e senzala. Formação da família brasileira sob o regime da economia patriarcal. Rio de Janeiro: José Olympio.

Rezende, Claudia Barcellos. (200I). Entre mundos: sobre amizade, igualdade e diferença. In: Velho, Gilberto \& Kuschnir, Karina (orgs.). Mediação, cultura e política. Rio de Janeiro: Aeroplano.

Velho, Gilberto. (2012). O patrão e as empregadas domésticas. Sociologia, Problemas e Práticas, 69, p. 13-30. 